\title{
Peran CELAC dalam Menangani Krisis Pangan di Haiti
}

Eka Safitri Minabari ${ }^{1}$, Farayani Hamin

ekasafitrimn@gmail.com, vha.hamin@gmail.com

\begin{abstract}
Abstrak
Penelitian ini berusaha untuk mengetahui peran Community of Latin American and Caribbean States (CELAC) dalam menjalankan program Zero Hunger di Haiti. Jika dibandingkan dengan negaranegara di kawasan Amerika Latin dan Karibia, Haiti merupakan negara yang memiliki tingkat kelaparan dan kekurangan gizi tertinggi. Hal ini menjadi dasar bagi CELAC untuk berperan dalam mengatasi persoalan tersebut. Dengan menggunakan metode studi dokumentasi dan konsep organisasi internasional yang dikemukakan oleh Clive Archer dan Andre Pariera, penelitian ini menghasilkan dua temuan mengenai peran CELAC dalam mengatasi masalah kelaparan dan kekurangan gizi di Haiti. Pertama, CELAC berperan sebagai arena dan aktor melalui pengadaan Konferensi Tingkat Tinggi dan Konferensi Tingkat Menteri yang membahas persoalan di Haiti. Kedua, CELAC berperan sebagai inisiator melalui promosi terhadap dialog antar negara.
\end{abstract}

Kata kunci: CELAC, FAO, Haiti, Zero Hunger

\begin{abstract}
This research attempts to understand the role of the Community of Latin American and Caribbean States (CELAC) in carrying out the Zero Hunger program in Haiti. Compared to the other countries in Latin America and the Caribbean, Haiti is the country that has the highest poverty and malnutrition rates. This becomes the basis for CELAC to take roles in the problem. By using research methods and international concepts proposed by Clive Archer and Andre Pariera, this study produces two findings about CELAC in overcoming problems related to malnutrition in Haiti. First, CELAC plays a role as an arena an actor through the provision of the High-Level Conference and Ministerial Conference that discusses the problems in Haiti. Second, CELAC has a role as an initiator through the promotion of dialogue between countries to exchange experiences on national social programs.
\end{abstract}

Keywords: CELAC, FAO, Haiti, Zero Hunger

\section{Pendahuluan}

Kelaparan merupakan permasalahan global yang dihadapi oleh banyak negara. Masalah kelaparan biasanya melanda negara-negara berkembang, meskipun pada kenyataannya negara-negara maju juga tidak luput dari permasalahan yang sama. Penyebab kelaparan yang paling utama adalah kemiskinan, kurangnya sumber daya baik dalam hal akses maupun kuantitas, hingga distribusi pendapatan yang tidak merata.

\footnotetext{
1 Korespondensi: Eka Safitri Minabari. Program Studi Hubungan Internasional, FISIP, UMM, Jl Raya Tlogomas 246 GKB 1 Lt6, 0341-464318 ext 135.
} 
(Bread for the World Institute). Berdasarkan data The United Nation Food and Agriculture Organization (FAO), pada tahun 2016 jumlah orang kelaparan di dunia berada pada angka 815 juta orang dari 7,6 miliar orang di dunia. Adapun pada tahun yang sama sebesar 10,7\% orang menderita kekurangan gizi kronis. Sebagian besar kondisi tersebut terdapat di negara-negara yang berpenghasilan menengah kebawah. (FAO, 2017). Berdasarkan sumber data yang sama, kawasan Asia memiliki jumlah tertinggi populasi kekurangan gizi yaitu sebanyak 519,6 juta jiwa, diikuti oleh Afrika 243,2 juta jiwa, serta Amerika Latin dan Karibia dengan angka 42,5 juta jiwa. (FAO, 2017)

Sementara itu, Global Hunger Index pada tahun 2018 merilis data 10 negara yang mengalami krisis kelaparan dengan persentasi jumlah kelaparan tertinggi. Menurut data tersebut Republik Afrika Tengah berada di peringkat teratas dengan tingkat kelaparan yang mencapai angka 61,8\%, diikuti oleh Chad (39,7\%), Yaman 34,4\%, Madagaskar (43,1\%), Zambia (43,1\%), Sierra Leone (25,5\%), Haiti (45,8\%), Sudan (25,2\%), Afganistan (30,3\%) dan Timor Leste (27,2\%). (Global Hunger Index, 2018) Meskipun berada pada peringkat ketujuh, Haiti memiliki jumlah populasi yang paling tinggi dibandingkan dengan sembilan negara lain yang disebutkan diatas. (CEIC, 2018)

Adanya krisis kelaparan di Haiti disebabkan oleh perubahan iklim dan kekeringan yang mengurangi kemampuan warga Haiti untuk menghasilkan makanan mereka sendiri. Krisis tersebut berawal pada tahun 2011, dimana pada saat itu Haiti menghabiskan lebih dari US $\$ 800$ juta per tahun untuk impor makanan bersubsidi yang biayanya sering menjadi penghalang bagi $80 \%$ populasi negara Haiti yang hidup dengan kurang dari \$2 sehari. Hal ini diperparah dengan adanya kekeringan yang menimpa Haiti pada tahun 2015 sebagai dampak dari musim kemarau "El Nino" yang bertahan sampai pada 2016. Sebelum terjadi krisis pangan, Haiti mengalami musibah gempa bumi pada tahun 2010. Musibah tersebut berdampak pada hancurnya sebagian besar bangunan di ibu kota Port-au-Prince yang menyebabkan 1,5 juta orang kehilangan tempat tinggal.

Adanya masalah kelaparan dan kekurangan gizi di Haiti membuat beberapa rezim atau organisasi internasional berupaya untuk membantu menangani masalah tersebut. Salah satu diantaranya ialah Sustainable Development Goals (SDGs) yang memiliki 
program "Zero Hunger" dengan tujuan mengakhiri semua bentuk kelaparan dan kekurangan gizi pada tahun 2030. (UNDP, 2012) Selain SDGs, terdapat juga The Community of Latin American and Caribbean States (CELAC) sebagai organisasi regional yang juga turut andil dalam membantu mengatasi masalah kelaparan di Kawasan Amerika Latin dan Karibia. Organisasi yang dibentuk pada tahun 2011 tersebut memiliki tujuan untuk melaksanakan program Zero Hunger di kawasan Amerika Latin dan Karibia (CELAC, 2011).

Penerapan program Zero Hunger di Haiti dijalankan oleh CELAC melalui kerjasama dengan Organisasi Internasional yang bergerak di bidang pangan yaitu Food and Agriculture Organization (FAO). Hal ini dikarenakan negara-negara di Kawasan Amerika Latin dan Karibia telah lebih dulu tergabung dalam FAO untuk membantu mengembangkan sektor pangan di negara mereka masing-masing. Dengan demikian, tugas CELAC dalam penerapan program Zero Hunger di Kawasan Amerika Latin dan Karibia adalah sebagai perpanjangan atau tindak lanjut program FAO yang telah diterapkan di kawasan tersebut dan dimaksimalkan dengan bantuan dan kontribusi Economic Commission fot Latin America and the Caribbean (ECLAC) serta Latin American Integration Association (ALADI) (CELAC FNS Plan 2025).

Berangkat dari latar belakang diatas, tulisan ini berupaya untuk mengetahui apa saja peran dari CELAC dalam mengatasi persoalan kelaparan dan kekurangan gizi di Haiti, terutama melalui pelaksanaan program Zero Hunger. Guna mempermudah pembahasan, tulisan ini akan penulis bagi dalam tiga bagian. Bagian pertama ialah tinjauan pustaka yang berisi pemaparan mengenai peran organisasi internasional. Bagian berikutnya ialah penjelasan mengenai metode penelitian yang digunakan. Bagian ketiga ialah hasil pembahasan dan diskusi. Bagian terakhir ialah kesimpulan.

\section{Tinjauan Pustaka}

\section{Peran Organisasi Internasional}

Secara umum organisasi Internasional dapat dipahami sebagai lembaga yang memiliki prosedur-prosedur formal dan keanggotaan yang mencakup tiga negara atau 
lebih. Organisasi Internasional memiliki kekuatan untuk mempengaruhi dalam dunia internasional. Organisasi Internasional memiliki kekuatan untuk menyediakan kerangka bagi kerjasama guna memecahkan berbagai masalah diantara negara-negara. Organisasiorganisasi internasional mampu berperan di ranah global dengan meminimalisir juga menghindari ancaman terbentuknya sebuah super-negara global atau regional. Organisasi internasional telah ada sejak Perang Dunia I yang ditandai dengan munculnya gelombang organisasi-organisasi internasional baru. (Heywood, 2016)

Karakteristik umum organisasi internasional dapat ditinjau dari segi: (1) keanggotaan, dimana terdapat kategori keanggotaan terbatas dan universal; (2) kompetensi, dimana kategori tanggung jawab organisasi internasional bersifat spesifik atau komperhensif; (3) Fungsi, dimana kategori fungsi Organisasi Internasional merupakan organisasi program atau organisasi operasional; dan (4) Otoritas pembuatan keputusan, dimana Organisasi Internasional merupakan contoh dari intergovernmentalisme atau supranasionalisme. (Heywood, 2016)

Peranan Organisasi Internasional menurut Clive Archer dapat dibagi kedalam 3 kategori, yaitu: (1) Sebagai instrumen, yaitu Organisasi digunakan oleh negaranegara anggotanya untuk mencapai tujuan tertentu atau sebagai instrumen kebijakan luar negeri negara anggota dan dapat membatasi tindakan-tindakan organisasi internasional peran organisasi internasional sebagai instrumen kebijakan luar negeri negara anggota maka hal tersebut dalam mempengaruhi organisasi dan kemampuannya dalam melaksanakan kebijakan yang disetujui oleh kolektivitas anggota dan mewakili seluruh kepentingan negara anggota. Maka Organisasi Internasional disini berfungsi sebagai sarana untuk mencapai kesepakatan, menekan intensitas konflik dalam pengambilan keputusan, serta menyelaskan tindakan semua anggota.; (2) Sebagai arena, yaitu Organisasi Internasional merupakan tempat bertemu bagi anggota-anggota untuk membicarakan dan membahas masalah-masalah yang dihadapi atau Organisasi Internasional memfasilitasi debat dan pertukaran informasi antar negara anggota; dan (3) Sebagai aktor, yaitu Organisasi Internasional dapat membuat keputusan-keputusan 
sendiri tanpa dipengaruhi oleh kekuasaan atau paksaan dari luar organisasi dan untuk memungkinkan negara-negara untuk melakukan aksi bersama. (Archer, 2001)

Organisasi Internasional tentunya memiliki peran baik secara spesifik dalam satu bidang tertentu maupun secara luas. Peran Organisasi Internasional menurut Andre Pariera dimana dijelaskan bahwa peran Organisasi Internasional secara spesifik dibedakan menjadi 5 bagian, yaitu inisiator, fasilitator, mediator atau rekonsiliator, dan determinator. Inisiator menunjukkan peran Organisasi Internasional dalam memprakasai kerja sama serta mengajukan suatu masalah maupun fenomena pada komunitas internasional untuk mencari solusi terhadap hal tersebut. Bentuk kerja sama ini bisa dilakukan dengan negara, organisasi, masyarakat ataupun komunitas, dan individu. Peran sebagai fasilitator adalah upaya untuk menyediakan fasilitas yang dibutuhkan untuk menyelesaikan masalah dan mencapai tujuan organisasi.Dalam konteks sebagai mediator atau rekosiliator, organisasi Internasional memiliki peran sebagai penengah dalam upaya menyelesaikan suatu masalah atau konflik antar anggotanya. Untuk peran sebagai determinator adalah upaya untuk memberi dan mengambil keputusan pada suatu masalah. (Pariera, 1999)

Berdasarkan teori organisasi internasional menurut Clive Archer, penulis ingin meninjau peran CELAC sebagai Arena dan juga Aktor dan untuk teori Organisasi Internasional menurut Andre Pariera penulis akan meninjau peran CELAC sebagai inisiator, fasilitator, dan determinator. Untuk peran mediator atau rekosiliator disini tidak tepat untuk melihat peran CELAC dalam menyelesaikan permasalahan kelaparan di Haiti karena masalah kelaparan Haiti merupakan masalah probadi salah satu negara anggota bukanlah masalah antar negara anggota CELAC sehingga tidak dapat meninjau peran CELAC sebagai mediator ataupun rekonsiliator.Dengan demikian, landasan teoritis tentang peran Organisasi Internasional dapat diaplikasikan untuk menggambarkan peran Food and Agriculture Organization (FAO) sebagai mitra kerja CELAC yang merupakan kategori Organisasi Internasional yang bergerak di bidang pangan dalam membantu mengatasi krisis pangandi Haiti. 
Sejalan dengan fenomena terjadinya krisis pangan secara global, Haiti yang merupakan salah satu negara di kawasan Amerika bagian tengah tepatnya di kawasan Karibia juga merasakan dampak dari krisis pangan tersebut. Kondisi demikian tidak lain disebabkan oleh perekonomian haiti yang cukup lemah, dan juga sulitnya beradaptasi terhadap ancaman ekonomi secara internal maupun eksternal. Jika dilihat dari sektor mata pencaharian utamanya, Haiti merupakan negara dengan mayoritas mata pencaharian pada sektor agrikultur. Meskipun masyarakat Haiti menggantungkan hidupnya pada sektor pertanian, namun masyarakat Haiti di kategorikan belum mampu memenuhi kebutuhan hidupnya. Hal ini dilihat dari perbandingan upah tetap yang di peroleh masyrakat hanyalah 1 orang dari 50 orang. Sehingga 49 sisanya berada pada kondisi tidak pasti dalam mendapatkan upah. Ketidakpastian upah yang di peroleh berimplikasi langsung dan mempengaruhi daya beli masyarakat dalam memenuhi kebutuhan hidupnya. Di Haiti sebagian besar masyarakat tidak memiliki pekerjaan. (Herlinger, 2016).

Krisis pangan yang ditandai dengan adanya kenaikan harga pangan secara drastis menjadi dampak besar ketika tidak disertai dengan kenaikan upah pekerja. Sebab kenaikan harga pangan berimplikasi pada kemampuan masyarakat dalam memenuhi kebutuhan pangan. Bahkan bank dunia menyatakan bahwa sekitar tiga per empat atau $75 \%$ masyarakat Haiti, hidup dengan pendapatan US $\$ 1,25$ perhari. Oleh sebab itu masyarakat sulit memenuhi kebutuhan pangannya akibat terbatasnya pendapatan. Krisis kelaparan yang teradi di Haiti di karenakan adanya kompleksitas masalah yang di alami Haiti. Tidak seperti negara lain pada umumnya negara haiti meiliki banyak masalah yang menyebabkan adanya krisis kelaparan salah satunya dari sisi geografis, rentan terhadap bencana alam dan faktor lainnya seperti instabilitas ekonomi. (Herlinger, 2016)

\section{Metode Penelitian}

Penelitian ini menggunakan metode studi dokumentasi dalam hal pengumpulan data, dengan memanfaatkan dan mengolah data dari situs resmi online pemerintahan negara-negara Amerika Latin dan Karibia, situs resmi beberapa organisasi 
diantaranya CELAC, FAO, Bread of The World, Global Hunger Index, UNDP, UN OCHA, dan beberapa Jurnal dari Global Press Journal dan jurnal economics of ariculture serta Artikel online yang terdapat dalam situs Down to Earth Organization dan situs Cite Seer Education yang dapat menunjang referensi penelitian ini. Dengan menggunakan konsep Organisasi Internasional menurut Clive Archer dan Andre Pariera.

\section{Hasil dan Pembahasan}

\section{Program Zero Hunger CELAC}

Program Zero Hunger adalah salah satu program Sustainable Development Goals yang digagas oleh PBB. Program ini dijalankan untuk mengakhiri kelaparan, mencapai keamanan pangan, peningkatan nutrisi, dan promosi pertanian berkelanjutan. Program ini menjadi sangat penting karena masalah kelaparan diperkirakan akan terus meningkat dan menambah jumlah orang dengan kekurangan gizi sebanyak 2 milyar orang pada 2050. Bersamaan dengan itu, sumber daya alam dan keanekaragaman hayati terus mengalami degradasi dan perubahan iklim yang memberikan tekanan pada sumber daya juga meningkatkan resiko bencana alam banjir dan kekeringan. Ketahanan pangan yang buruk menyebabkan jutaan anak menjadi kerdil karena kekurangan gizi. (Lam, Hunger Notes, 2018).

Program ini diadopsi dan dijadikan sebagai fokus dan dibantu oleh beberapa organisasi seperti International Fund for Agricultural Development (IFAD), Food and Agriculture Organization (FAO), World Food Programme (WFP), UNICEF-Nutrition, dan lain sebagainya. Beberapa organisasi regional juga membangun kerjasama dengan organisasiorganisasi ini dan beberapa organisasi regional mengadopsi program ini secara langsung untuk diterapkan di negara-negara kawasan dan dijadikan visi organisasi. Seperti halnya organisasi regional Amerika Latin dan Karibia (CELAC) yang mempromosikan program Zero Hunger secara umum sebagai visi 2030 nya. Bedanya CELAC secara khusus membuat rencana Food Security, Nutrition, dan Hunger Eradication Tahun 2025 (CELAC FNS PLAN 2025) pada KTTT ketiga, Januari 2015 di Kosta Rika. Visi ini pertama kali dinyatakan dalam Deklarasi pertama CELAC di Caracas yang menyatakan komitmen 
untuk “...promote food and nutritional security”. Selain itu, mekanisme untuk kerjasama antara CELAC dan FAO terkait FNS PLAN juga telah dibuat.

Beberapa pilar terkait rencana CELAC menerapkan program Food Security, Nutrition, dan Hunger Eradication Tahun 2025 (CELAC FNS PLAN 2025) yang berfokus pada keamanan pangan diantaranya adalah: Pertama, berusaha menciptakan strategi keamanan pangan yang terkoordinasi melalui rencana nasional dan regional juga kebijakan publik. Pilar ini akan memperkuat kerangka hukum dan kelembagaan untuk ketahanan pangan, memfasilitasi perdagangan, menghindari kehilangan dan pemborosan pangan, dan mempromosikan program penyediaan makanan; Kedua, berusaha memastikan akses berkelanjutan ke makanan yang aman dan bergizi untuk semua orang dengan rencana penerapan program transfer tunai bersyarat dan melalui penguatan pasar tenaga kerja dan proyek pertanian keluarga; Ketiga, mencari kesejateraan nutrisi untuk semua kelompok rentan melalui inisiatif memberi makan di sekolah, mempromosikan kebiasaan-kebiasaan sehat, dan mengurangi beban kembar kekurangan gizi yaitu obesitas dan kekurangan gizi; dan Keempat, berusaha menjamin stabilitas produksi pangan dan perawatan tepat waktu untuk bencana alam. Pilar ini telah disahkan pada KTTT Habana pada tahun 2014.

Terkait dengan FNS Plan ini, CELAC menyebutkan mitra kerjasama utamanya yaitu FAO dengan beberapa organisasi Kawasan Amerika seperti ALADI dan ECLAC. Kedua organisasi regional tersebut diminta secara khusus oleh CELAC untuk memberikan sebuah proyek untuk rencananya yaitu Rencana Ketahanan Pangan, Gizi, dan Pemberantasan Kelaparan untuk diperdebatkan selama pertemuan teknis perwakilan pemerintah. Rencana tersebut nantinya akan dipresentasikan dalam Pertemuan II Menteri Pembangunan Sosial dan Pemberantasan Kelaparan.

\section{Mekanisme Kerjasama CELAC dan FAO}

Food and Agriculture Organization (FAO) merupakan badan khusus Perserikatan Bangsa-bangsa (PBB) yang memimpin upaya internasional untuk memberantas kelaparan. Tujuan utama FAO adalah mencapai ketahanan pangan untuk semua penduduk negara di dunia dan memastikan bahwa orang-orang memiliki akses 
untuk makanan yang berkualitas tinggi dan cukup untuk menjalani kehidupan yang aktif dan sehat. FAO menjalankan tugasnya di negara-negara anggota dengan mengidentifikasi prioritas-prioritas utama disesuaikan dengan negara-negara yang paling membutuhkan bantuannya untuk membantu mengatasi masalah kelaparan dan kekurangan gizi. FAO merupakan organisasi yang memiliki anggota berupa negara dan memiliki tugas untuk mendukung negara-negara yang menjadi anggotanya dalam upaya untuk memastikan bahwa setiap orang memiliki akses ke makanan yang berkualitas tinggi yang cukup. FAO membantu negara anggota dengan mendukung kebijakan dan komitmen politik yang mempromosikan ketahanan pangan dan nutrisi yang baik dan selalu memperbaharui informasi terkini tentang tantangan dan solusi kelaparan dan kekurangan gizi yang tersedia dan dapat diakses oleh negara anggota.

Fokus FAO adalah untuk mengembangkan pertanian, kehutanan, dan perikanan secara berkelanjutan. Hal ini dilatarbelakangi oleh perkiraan dimana populasi dunia diperkirakan akan meningkat menjadi 9 miliar orang pada tahun 2050. Tingkat pertumbuhan populasi tertinggi di dunia juga diperkirakan terjadi di daerah yang sangat tergantung pada sektor pertanian (tananman, ternak, kehutanan, dan perikanan) dan negara-negara yang memiliki tingkat tinggi kerawanan pangan. Jadi pertumbuhan di sektor pertanian adalah salah satu cara paling efektif untuk mengurangi kemiskinan dan untuk mencapai ketahanan pangan yang stabil dan berkelanjutan.

Selain untuk mengembangkan pertanian, kehutanan, dan perikanan, FAO memiliki fokus untuk mengurangi kemiskinan pedesaan. Hal ini berlandaskan alasan bahwa kelaparan dan kerawanan pangan disebabkan oleh kemiskinan pedesaan. FAO berupaya untuk membantu petani kecil meningkatkan produktivitas pertanian dan juga berupaya untuk meningkatkan peluang kerja di luar pertanian serta membantu penduduk pedesaan menemukan cara yang baik untuk mengelola dan mengatasi resiko di lingkungan pedesaan. Fokus FAO lainnya yaitu untuk mewujudkan sistem pertanian dan pangan yang insklusif dan efisien, dimana FAO ingin mengembangkan akses petani kecil di pedesaan negara-negara berkembang agar mampu meningkatkan partisipasi mereka dalam sistem pangan dan pertanian nasional maupun global. 
Fokus FAO yang terakhir adalah untuk meningkatkan ketahanan mata pencaharian terhadap ancaman dan krisis dimana ancaman atau krisis berupa gempa bumi, banjir, kekeringan dapat menyerang secara tiba-tiba dan akan memiliki dampak terhadap pertanian dan mata pencaharian penduduk yang memiliki kontak langsung dengan alam. Disini FAO memiliki misi untuk mengatur, mencegah, dan mengurangi resiko dan krisis serta mendukung suatu negara dalam mempersiapkan dan menanggapi bencana. (FAO, 2018)

Di kawasan Amerika Latin dan Karibia Pada tahun 2005, FAO membentuk komitmen bersama dengan negara-negara Kawasan Amerika Latin dan Karibia melalui Hunger-Free Latin America and the Caribbean Initiative (HFLACI) dengan tujuan memberantas kelaparan. Peran FAO di sini adalah mendukung Working GroupFamily Farming and Rural Development (WG-FF) atau Kelompok Kerja Pertanian Keluarga dan Pembangunan Pedesaan melalui pejabat yang ditunjuk dengan memberikan saran strategis untuk proses penerapan Strategi Regional tentang agenda Food Security, Nutrition, dan Hunger Eradication Tahun 2025. FAO juga mendukung proposal strategi dari Kementrian Pertanian Organisasi CELAC melalui Komite Teknis adhoc terkait dengan Disaster Risk Management (DRM) atau Manajemen Resiko Kerusakan yang berasal dari alam dan bencana alam. (FAO, 2018)

\section{Peran CELAC dan FAO dalam penerapan program Zero Hunger}

Amerika Latin dan Karibia adalah wilayah yang membuat kemajuan terbesar dalam mengurangi kelaparan, dapat dijadikan aktor terkemuka, dan contoh bagi seluruh dunia. Kawasan ini menjadi satu-satunya kawasan berkembang yang mencapai target kelaparan Millenium Development Goals (MDGs) dengan jumlah tingkat kekurangan gizi dari 15,3\% pada tahun 1990-1992 menjadi 6,1\% pada tahun 2012-2014. Kawasan ini juga sebelumnya memenuhi tujuan World Food Summit (WFS) dengan mengurangi kekurangan gizi menjadi 34,3 juta. Setelah dua keberhasilan telah tercapai, kawasan ini melalui organisasi CELAC kemudian menerapkan komitmen baru untuk mencapai Zero Hunger. Dengan adanya penurunan jumlah kelaparan yang signifikan tersebut, CELAC optimis 
bahwa jumlah tersebut akan bisa dikurangi lagi dengan adanya CELAC FNS PLAN 2025.

KTT CELAC kelima pada tanggal 25 Januari 2017 di Republik Dominika menyebutkan bahwa implementasi rencana Food Security, Nutrition, dan Hunger Eradication Tahun 2025 (CELAC FNS PLAN 2025) akan berjalan dengan dukungan dari FAO, ECLAC dan ALADI untuk menyesuaikan agenda SDGs pada 2030. CELAC FNS PLAN 2025 meliputi rencana pembuatan kelompok kerja untuk kemajuan perempuan, pengembangan usaha pertanian skala menengah (UKM) dan kelompok-kelompok petani keluarga. Selain itu, CELAC mendukung tindakan-tindakan untuk mengatasi semua bentuk kekurangan gizi, khususnya pada anak usia dini, termasuk pengembangan kegiatan pelatihan pejabat publik yang bertanggung jawab untuk mengadopsi langkahlangkah untuk pengimplementasian bertahap hak atas nutrisi yang sehat dan untuk LSM yang menyediakan bantuan jasa makanan.

CELAC juga merencanakan promosi dialog tentang kebijakan publik yang ditujukan untuk keamanan pangan dan peningkatan gizi. Terkait dengan pertanian keluarga, CELAC menggelar Pertemuan Tingkat Menteri ke-4 tentang Pertanian Keluarga dan Pembangunan Pedesaan pada November 2017 di Venezuela dengan dukungan dari FAO. Penerapan strategi sebagai bentuk peran CELAC dalam mengatasi kelaparan dan menerapkan program Zero Hunger adalah penerapan 4 strategi utama yaitu: (1) Diversification of Agricultural Production atau Diversifikasi Produksi Pertanian; (2) Sustainable Farm Management atau Pengelolaan Pertanian Berkelanjutan; (3) Identify and Support Local Producers Organization atau Identifikasi dan Dukungan kepada Organisasi Produsen Lokal; dan (4) Support Establishment of Agro-Industry atau Dukungan terhadap Pendirian Agroindustri. (FAO)

Pertama, strategi Diversifikasi Produksi Pertanian yang berkaitan dengan produksi makanan kebun skala kecil seperti sayuran dan buah-buahan di tingkat rumah tangga atau keluaraga dengan menyewakan lahan untuk produksi mandiri makanan keluarga dan memberikan pelatihan pendidikan gizi dan sanitasi oleh pelatih lokal. Kedua, strategi Pengelolaan Pertanian Berkelanjutan terkait dengan produksi kebun dan 
makanan pada tingkat rumah tangga atau keluarga dengan menyewakan lahan pertanian yang lebih luas digunakan unruk produksi makanan pokok dan bisa juga dimanfaatkan sebagai peternakan unggas atau peternakan besar. Strategi ini difasilitasi tentunya dengan pelatihan dan pendampingan oleh fasilitator lokal.

Ketiga, strategi Identifikasi dan Dukungan kepada Organisasi Produsen Lokal. Strategi ini berkaitan dengan hasil pertanian yang dipasarkan, yang mana menuntut masyarakat agar memberikan dukungan terhadap pembentukan komite produsen lokal untuk berbagai jenis produk yang dapat menjadi koperasi pertanian dalam jangka panjang. Keempat strategi Dukungan terhadap Pendidrian Agroindustri yang berkaitan dengan program jangka panjang dan melampaui koperasi pertanian fungsional dengan tujuan menggabungkan beberapa koperasi pertanian yang mewakili rantai produksi dari satu atau beberapa tempat produksi. Strategi ini mempertimbangkan penerapan sertifikasi pada produk yang dihasilkan agar dapat menjangkau pasar nasional dan internasional, dan juga dapat menciptakan lapangan kerja untuk penduduk setempat dan dapat memberikan sumber penghasilan tambahan untuk komunitas.

CELAC merumuskan kebijakan publik untuk menghadapi tantangan keamanan pangan dengan pendekatan gender dan perspektif Hak Asasi Manusia atas makanan dengan melakukan konsesnus tentang prioritas kebutuhan makanan melalui penelitian rantai makanan dan protokol penjualan makanan. Selain itu, CELAC menciptakan akses tepat waktu dan berkelanjutan untuk makanan bergizi dengan memperkuat pengembangan pertanian keluarga, membangun kapasitas manajemen resiko serta pengadopsian teknologi.

CELAC menetapkan kebijakan Conditional Transfer Programs (CTP) untuk seluruh anggotanya tidak terkecuali Haiti. Program ini merupakan program perlindungan sosial di kawasan dengan membantu menyediakan tingkat konsumsi dasar dan memfasilitasi akses ke layanan sosial di bidang kesehatan, pendidikan, dan gizi. Dalam hal ini CELAC mempromosikan jalannya dialog antar negara untuk bertukar pengalaman mengenai program sosial nasional terkait dengan pemberantasan kelaparan dan kemiskinan terutama kemiskinan ekstrim. 
Peran CELAC yang lain adalah mendukung secara resmi kerja United Nation Stabilization Mission in Haiti (MUNISTAH). Dukungan ini bertujuan untuk membantu menyelesaikan permasalahan krisis kelaparan di Haiti dengan menyelesaikan terlebih dahulu beberapa akar penyebab krisis kelaparan yaitu konflik yang dilakukan oleh pejuang oposisi Haiti di ibukota Haiti Port-au-Prince. CELAC menyatakan dukungannya dan menyatakan memberikan perhatian khusus. CELAC berkomitmen untuk membantu Haiti kembali ke keadaan yang stabil, damai, sehingga dapat menjalankan pembangunan berkelanjutan. Untuk tujuan itu, CELAC memberikan kontribusi mayoritas pasukan tentara serta personel polisi dari negara Brazil, Argentina, Uruguay, dan Chile sebanyak 85\% ke MUNISTAH untuk menyelesaikan konflik yang secara langsung berdampak terhadap krisis kelaparan di Haiti. Dukungan dan bantuan ini diberikan untuk melengkapi kebutuhan sumber daya dan agar dapat lebih disambut oleh pemerintah Haiti. (CELAC, 2012)

Penulis disini melihat peran daripada CELAC saat bermitra dengan FAO untuk mencapai program Zero Hunger di negara Haiti. Bantuan yang diberikan pada negara Haiti berfokus pada empat bidang prioritas utama, yaitu: (1) Pengembangan kapasitas untuk kebijakan dan stategi untuk ketahanan pangan dan nutrisi; (2) Mempromosikan sektor pertanian melalui investasi swasta dan publik serta layanan dukungan pertanian; (3) Meningkatkan kapasitas pengelolaan Sumber Daya Alam dan ketahanan terhadap perubahan iklim; dan (4) Memperkuat kapasitas manajemen resiko untuk bencana alam dan krisis pangan.

FAO juga menerapkan program Road to Recovery di Negara Haiti dan telah memberikan hasil signifikan terhadap pengurangan tingkat kerawanan pangan dengan membangun kembali irigasi dan mengakses jalan, memperkuat tepian sungai dan aliran sungai, dan meluncurkan kembali kegiatan yang terkait dengan pengelolaan daerah aliran sungai, khususnya penanaman pohon, untuk mencegah banjir (FAO, 2015). Penekanan program FAO telah bergeser daripada program umum diarahkan kepada program yang lebih khusus. Kerjasama FAO lebih dipusatkan pada bantuan pertanian darurat. 
Penekanannya adalah pada rantai nilai pertanian, pengelolaan dan pengembangan daerah aliran sungai, dan pembangunan ketahanan dalam menghadapi perubahan iklim.

Dalam konteks Organisasi Internasional, FAO sebagai sebuah organisasi internasional yang memfokuskan pada bidang pangan berupaya mengatasi krisis kelaparan yang terjadi di Haiti dengan mengimplementasikan visi dan misinya melalui program yang FAO sepakati dengan pihak pemerintah Haiti. Salah satunya adalah dengan diciptakannya respon yang cepat dan tanggap terhadap bencana. Selain itu, FAO sebagai instrumen dalam mencapai suatu misi tertentu di gambarkan oleh FAO dalam menginisiasi program intervensi pangan sebagai bentuk upaya dalam menyelesaikan krisis pangan di Haiti.

Peran FAO sebagai arena ialah menjadi forum yang berfungsi sebagai tempat untuk melakukan koodrinasi dan juga kerjasama yang di selenggarakan bersama. Koordinasi dan kolaborasi yang di lakukan antara lain dengan United State Agency for International Development (USAID), CARE internasional dan juga Canada sebagai salah satu pendonor. Selain itu melalui peran ini FAO juga melakukan penggalangan donasi terbuka untuk semua pihak dalam rangka membantu mengatasi krisis pangan di haiti yang membutuhkan biaya cukup besar.

FAO sebagai aktor independen memiliki wewenang terkait dengan tindakantindakan apa saja yang bisa di lakukan di Haiti pasca terjadinya krisis. Contoh dari tindakan yang di lakukan yakni pembangunan kapasitas nasional, dimana Haiti yang merupakan negara dengan kondisi pemerintahan lemah, sangat memerlukan bantuan untuk memperkuat institusi pemerintahan. FAO juga aktif dalam forum-forum diskusi internasional dan menjalin kerja sama dengan aktor internasional lainnya, khususnya dalam mengatasi krisis kelaparan. Hal ini sesuai dengan peran organisasi internasional sebagaimana yang telah di klarifikasikan oleh Clive Archer.

Sesuai dengan teori Organisasi Internasional menurut Clive Archer, peran CELAC sebagai Arena adalah mengadakan Konferensi Tingkat Tinggi dan Konferensi tingkat Menteri untuk merumuskan peran dan langkah-langkah yang harus diambil terkait jalannya CELAC FNS PLAN 2025 yang dilakukan pada KTT ke lima CELAC 
dan Pertemuan Tingkat Menteri ke empat tentang Pertanian Keluarga dan Pembangunan Pedesaan pada November 2017 di Venezuela. Peran CELAC sebagai Aktor adalah dimana CELAC memberi keputusan-keputusan terkait kebijakan-kebijakan keberlangsungan program FNS tanpa melibatkan organisasi lain, setiap KTT yang dilakukan adalah antara negara anggota. Beberapa Organisasi lain yang terlibat terutama FAO adalah hanya bersifat sebagai pendukung program FNS CELAC.

Peran CELAC jika ditinjau dari teori Organisasi Internasional menurut Andre Pariera adalah sebagai inisator, dimana CELAC menetapkan kebijakan Conditional Transfer Programs (CTP) untuk seluruh anggota organisasinya tidak terkecuali Haiti. Program ini merupakan program perlindungan sosial di kawasan dengan membantu menyediakan tingkat konsumsi dasar dan memfasilitasi akses ke layanan sosial di bidang kesehatan, pendidikan, dan gizi. Dalam hal ini CELAC mempromosikan jalannya dialog antar negara untuk bertukar pengalaman menganai program sosial nasional terkait dengan pemberantasan kelaparan dan kemiskinan terutama kemiskinan ekstrim. Selain itu, sebagai inisiator, CELAC memfasilitasi untuk membangun kerjasama dengan FAO.

Sebagai fasilitator, peran CELAC adalah mendukung secara resmi kerja United Nation Stabilization Mission in Haiti (MUNISTAH). CELAC berkomitmen untuk membantu Haiti kembali ke keadaan yang stabil, damai, sehingga dapat menjalankan pembangunan berkelanjutan. Untuk tujuan itu, CELAC memberikan kontribusi mayoritas pasukan tentara serta personel polisi dari negara Brazil, Argentina, Uruguay, dan Chile sebanyak 85\% ke MINUSTAH untuk menyelesaikan konflik yang secara langsung berdampak terhadap krisis kelaparan di Haiti.

\section{Kesimpulan}

CELAC memiliki visi yang mendukung misi SDG yaitu Zero Hunger. Visi yang CELAC rumuskan yaitu CELAC FNS PLAN 2025 untuk menangani masalah kelaparan dan kekurangan gizi di Kawasan Amerika Latin dan Karibia. salah satu negara anggota CELAC yang mengalami krisis kelaparan terberat adalah Haiti. Dalam hal ini CELAC berperan sebagai Arena adalah CELAC adalah mengadakan Konferensi Tingkat 
Tinggi dan Konferensi Tingkat Menteri yang dapat membantu Haiti untuk terlibat dalam forum untuk membahas permasalahan di negaranya. Sebagai Aktor, CELAC mampu mengambil keputusan hanya berdasarkan keputusan negara anggotanya tanpa campur tangan dari organisasi lain. Sebagai inisiator, CELAC menetapkan kebijakan Conditional Transfer Programs (CTP). Dalam hal ini CELAC mempromosikan jalannya dialog antar negara untuk bertukar pengalaman menganai program sosial nasional terkait dengan pemberantasan kelaparan dan kemiskinan terutama kemiskinan ekstrim. Sebagai fasilitator, peran CELAC adalah mendukung secara resmi kerja United Nation Stabilization Mission in Haiti (MUNISTAH).

\section{Ucapan Terima kasih}

Artikel ini merupakan hasil dari tugas mata kuliah HI Kawasan Amerika yang diampu oleh Ibu Demeiati Kusumaningrum, MA. Dengan ini penulis memberikan apresiasi setinggi-tingginya kepada beliau atas bimbingan dan ilmu yang telah diberikan selama perkuliahan berlangsung. Ucapan terima kasih juga penulis sampaikan kepada Dewan Editor dan Reviewer Jurnal Sospol yang telah memberikan arahan serta masukan yang bermanfaat, sehingga dapat dijadikan catatan untuk penulis agar dapat menghasilkan karya yang layak dipublikasikan.

\section{Daftar Rujukan}

\section{Buku}

Archer, C. (2001). International Organization (3 ed.). New York: Routledge.

Heywood, A. (2016). Politik Global (Kedua ed.). Yogyakarta: Pustaka Pelajar.

Perwita, D. A., \& Yani, D. Y. (2014). Pengantar Ilmu Hubungan Internasional. Bandung: Rosdakarya.

\section{Jurnal}

Cristina Netescu, 2010, Global Food Crisis from Causes to Remidies. Journal Economics of Agriculture, Vol.59 Issues.3 hal.181-182. 
Herjuno Ndaru K., \& Intan Defrina. (2005, November). Peran FAO dalam Penanganan Krisis Pangan dan Kelaparan: Studi Kasus Silent Hunger di Niger. Global Vol.8 No.1.https://doi.org/10.7454/global.v8i1.247

\section{Artikel Daring}

Bread for the World Institute. (n.d.). About Hunger. Bread for the World. Diakses 31 Mei, 2019, pada https://www.bread.org/where-does-hunger-exist

CEIC. (2018). CEIC Data. Diakses 7 Juni 2019, pada https://www.ceicdata.com/id/countries

CELAC. (2011). CELAC. CELAC Organization, Diakses 20 Oktober 2018, pada http://celacinternational.org/celac-2-2/

CELAC. (2012, Mei 7). Statement by the Permanent Representative of Chile Ambassador Octavio Errazuriz. Static. Diakses 7 Juni 2019, pada https://static.un.org/en/ga/fifth/66/Statements/000\%20Organization\%20 of\%20Work/C5_66_2r_ST_2012_05_07_Org_of_work_Chile.pdf

Charles, R. (2017, Agustus 8). Facing Food Shortage and Weather Crises, Haitian Farmers Say Government Support is Insufficient. Global Press Journal. (A. Branden, Ed., \& N. Sylvestre, Trans.) Haiti.

Charles, R. (2017, Agustus 8). Facing Food Shortage and Weather Crises, Haitian Farmers Say Government Support is Insufficient. Global Press Journal. Diakses $\quad 30 \quad$ Desember2018, pada https://globalpressjournal.com/americas/haiti/facing-food-shortageweather-crises-haitian-farmers-say-government-support-insufficient/

DOALOS United Nation. (2011). Division for Ocean Affairs and the Law of the Sea, UN. Maritime Space: Maritime Zones and Maritime Delimitation: Diakses 20 Desember 2018, pada http://www.un.org/Depts/los/LEGISLATIONANDTREATIES/caribbe an_states.htm 
FAO. (2015). Regional Overview of Food Insecurity Latin America and the Caribbean. Food and Agriculture Organization of the United Nation.

FAO. (2015). The Community Of Latin American And Caribbean States And Fao Partnering for Food Security, Sustainable Development and a Future Free from Hunger.

FAO. (2017). The State of Food Security and Nutrition in The World.

FAO.(2018). About FAO. Food and Agriculture Organization of The United Nation. Diakses 27 Desember 2018, pada http://www.fao.org/about/what-we-do/en/

FAO. (2018). Regional Strategy for Disaster Risk Management in the Agriculture Sector and Food and Nutrition Security in Latin America and the Caribbean (2018 2030).

FAO. (n.d.). FAO and EU Partnership. Diakses padahttp://www.fao.org/europeanunion/eu-projects/first/en/

Global Hunger Index. (2018). 2018 Global Hunger Index Result.Global Hunger Index. Diakses 7 Juni 2019, pada https://www.globalhungerindex.org/results/

Global Sister, Ministry.

Lam, C. (2018). Hunger Notes.World Hunger.Diakses November 2018, pada https://www.worldhunger.org/world-hunger-and-poverty-facts-andstatistics/\#hunger-number

Nicole Rencoret. (2010).Haiti Earthquake Response, Context Analysis. Diakses padahttp:/ / citeseer.ist.psu.edu/viewdoc/download?doi=10.1.1.176.2823\&re p1\&type $=$ pdf diakses pada 30/12/18 (20.10 WIB).

Niyogi, D. G. (2016, Agustus 16). CLIMATE CHANGE. Down to Earth. Diakses 25 November 2018, pada https://www.downtoearth.org.in/news/climatechange/climate-change-threatens-food-security-in-latin-america-and-thecaribbean-55297

Pariera, A. (1999). Perubahan Global dan Perkembangan Studi Hubungan Internasional. Bandung: PT. Bakti. 
The Dialogue. (2016, Februari 13). Beyond MINUSTAH: What can Latin America do for Haiti?.The Dialogue. Diakses 8 Juni 2019, pada https://www.thedialogue.org/blogs/2016/02/beyond-minustah-what-canlatin-america-do-for-haiti/

UNDP. (2012). Goal 2: Zero Hunger. Sustainable Development Goals. Diakses 25 November 2018, from https://www.un.org/sustainabledevelopment/hunger/

UN OCHA. (2016, Januari). Humanitarian Bulletin Haiti: Diakses 31 Desember 2018, pada https://reliefweb.int/sites/reliefweb.int/files/resources/ocha_haiti_humani tarian_bulletin_57-january_2016.pdf 